\title{
Rare case of heterotopic pregnancy: a case report
}

\author{
Rosy Khanam*, Shabir A. Choudhury
}

Department of Obstetrics and Gynecology, Silchar Medical College and Hospital, Silchar, Assam, India

Received: 20 December 2021

Accepted: 18 January 2022

\author{
*Correspondence: \\ Dr. Rosy Khanam, \\ E-mail: khanamrosy7@gmail.com
}

Copyright: ( the author(s), publisher and licensee Medip Academy. This is an open-access article distributed under the terms of the Creative Commons Attribution Non-Commercial License, which permits unrestricted non-commercial use, distribution, and reproduction in any medium, provided the original work is properly cited.

\begin{abstract}
Heterotopic pregnancy refers to condition where two pregnancies are present simultaneously at different implantation sites mostly manifested as intrauterine and ectopic pregnancies. First heterotopic pregnancy after in vitro fertilization was reported in 1972. Mostly it is a sporadic condition. The most common ectopic site is the fallopian tube, both in spontaneous and assisted reproductive technology (ART) heterotopic pregnancies. Almost $60-70 \%$ of heterotopic cases result in live childbirth with outcomes similar to that of singleton pregnancies. Spontaneous heterotopic pregnancy is a rare and potentially dangerous condition in which intrauterine (IU) and extrauterine pregnancies occur at the same time. It can be a life-threatening condition and can be missed, with the diagnosis being overlooked. A high suspicion is needed in women with risk factors for an ectopic pregnancy and in low-risk women with an intrauterine gestation who have free fluid with or without an adnexal mass or in those presenting acute abdominal pain and shock. The ectopic component is usually treated surgically and the intrauterine one is expected to continue normally.
\end{abstract}

Keywords: Heterotopic pregnancy, Intrauterine, Extrauterine pregnancy, Ectopic pregnancy

\section{INTRODUCTION}

Heterotopic pregnancy (HP) is a rare condition where at least two pregnancies are present simultaneously at different implantation sites mostly manifested as intrauterine and ectopic pregnancies. Its prevalence varies from 1 to 30000 in a natural cycle to around 1 in 100 in an assisted ones. ${ }^{1}$ Heterotopic pregnancies have been diagnosed from 5-34 weeks of gestation with up to $70 \%$ diagnosed between 5-8 weeks of gestation, $20 \%$ between 9-10 weeks, and only $10 \%$ after the $11^{\text {th }}$ week.

In 1972, first heterotopic pregnancy after in vitro fertilization was reported. ${ }^{2}$ It is a sporadic condition but is becoming more common after assisted reproductive technology (ART). The most common ectopic site is the fallopian tube, both in spontaneous and ART heterotopic pregnancies. The cornual site is the second most common site, while heterotopic in the cervix, ovary, and abdomen is extremely rare. Almost $60-70 \%$ of heterotopic cases result in live childbirth with outcomes similar to that of singleton pregnancies. A delayed diagnosis can result in increased rates of morbidity and mortality both for the mother and intrauterine gestation. ${ }^{3,4}$

\section{CASE REPORT}

In September 2021, a 35 year old, 8 weeks pregnant, otherwise healthy female presented to our emergency department with right-sided abdominal pain that radiated from the lower to upper quadrant. The pain was described as sharp and the patient had associated nausea and vomiting. She had a similar pain (less intense) about a month ago and was treated for cystitis. The patient denied any vaginal bleeding and had no history of reproductive medications and/or procedures. She was P0+1L0 (spontaneous abortion 6 months back). On examination there was significant diffuse abdominal tenderness, especially in the right upper quadrant (RUQ), with no rebound tenderness and a blood pressure of $96 / 50 \mathrm{mmHg}$ and heart rate of $98 / \mathrm{min}$. Initial investigations included a urine for beta-human chorionic gonadotropin (hCG), 
complete blood count (CBC), w/diff, lipase, urinalysis followed by a bedside ultrasound. Laboratory tests revealed haemoglobin $(\mathrm{Hb})$ of 8 (previous $\mathrm{Hb}$ was 11 from five days prior) and sodium of 133. Rest all lab tests were within normal limits. Bedside ultrasound demonstrated an intrauterine pregnancy (IUP) with heart rate (HR) of 185 bpm. Initial management included intravenous normal saline, as well as medication for pain and nausea. After all initial reports were available, ultrasounds of the kidneys, uterus and appendix were ordered due to concern for other causes of right sided abdominal pain such as appendicitis, cholecystitis, ovarian torsion, and nephrolithiasis. They were significant for free fluid and an ill-defined $5.1 \times 4 \mathrm{~cm}$ thick walled gestational sac with an internal embryo showing cardiac activity with fetal heart rate (FHR) of 185 bpm corresponding to 8 weeks 5 days noted in right adnexa and post-operative day (POD). While fluid resuscitation and pain management was continued and the patient remained hemodynamically stable. The patient experienced worsening pain and a drop in $\mathrm{Hb}$ to 7.3 with fall in blood pressure to $80 / 50 \mathrm{mmHg}$, pulse rate of $120 /$ min and drop in $\mathrm{SpO}_{2}$ to $84 \%$. Decision was taken to immediately operate on the patient with 2 units packed red blood cells (PRBC) in hand.

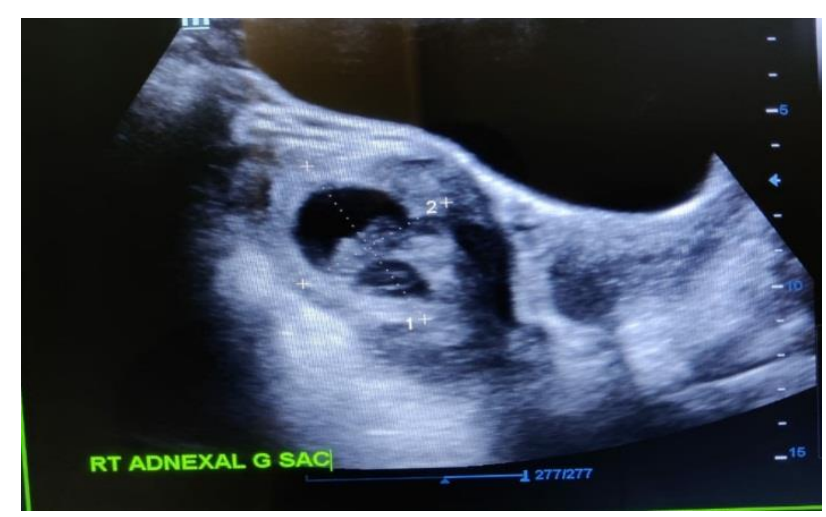

Figure 1: Right adnexal gestational sac (ectopic pregnancy).

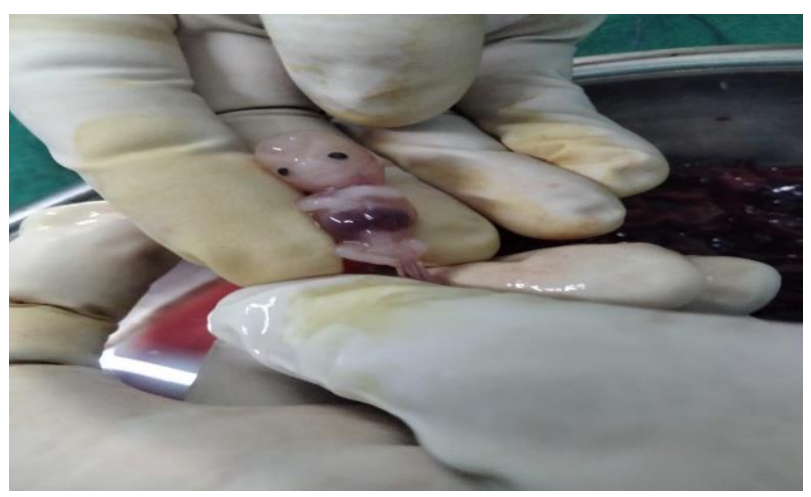

Figure 2: Fetus corresponding to approximately 8 weeks gestation.

During laparotomy, we found approximately $500 \mathrm{ml}$ of blood and clot in the abdomen with bright red blood filling in evacuated spaces concerning for active hemorrhage.
The right fallopian tube was visualized and an ectopic pregnancy was visualized and found to be actively hemorrhaging. The ectopic pregnancy was removed with a right salpingectomy. The tissue was sent to pathology, which confirmed the diagnosis of an ectopic tubal pregnancy, which in this patients setting made the diagnosis a heterotopic pregnancy. The patient was stabilized and discharged after 3 days and continues to have a healthy IUP in her second trimester at the time of this submission.

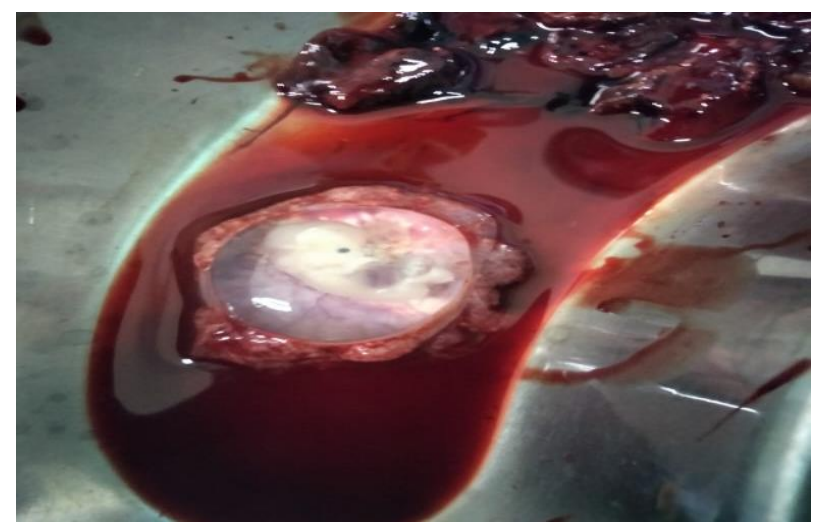

Figure 3: Gestational sac with embryo inside.

\section{DISCUSSION}

Heterotopic pregnancy refers to an intrauterine and extrauterine pregnancy. Most commonly these locations are the uterus and fallopian tube, but this is not always the case, with some cases reporting the ectopic pregnancy in other areas such as the abdomen. Before the age of ART, the incidence of heterotopic pregnancy was approximately 1 in 30,000. Since ART however, that incidence has become much frequent, around 1 in 3900. If the patient is undergoing ART the incidence is approximately 1.5 in 1000 pregnancies..$^{5-7}$ The patient's symptoms are often very similar to an ectopic pregnancy and they typically present with abdominal pain that may be localized or diffuse. On pelvic exam the physician may feel an adnexal mass or an enlarged uterus. Vaginal bleeding can also be present. Depending on the stage of illness the patient may also be peritoneal and hypotensive. There are no physical exam/lab findings that are specific for heterotopic pregnancy but this diagnosis should be considered in any hypotensive pregnant patient with abdominal pain and an IUP identified on bedside ultrasound, especially in the setting of free fluid on ultrasound and/or history of ART. ${ }^{8}$ The differential diagnosis of abdominal pain in pregnancy is wide. Once an IUP has been confirmed, diagnoses of appendicitis, kidney stone (especially if infected), pyelonephritis, gallbladder disease, ovarian torsion, endometritis, and heterotopic pregnancy should be considered as these could all have high morbidity/mortality for patients if not diagnosed. The diagnosis of heterotopic pregnancy is especially difficult, as it cannot be easily determined by serial $\beta$-hCG. Some literature has suggested ultrasound for the diagnosis, but 
various case reports, including this one, continue to demonstrate its low overall sensitivity. This may be partially due to the confirmation of an IUP often giving a sense of false security, which can lead to the misdiagnosis of the patient's abdominal pain. Because of this, late diagnosis and rupture is common in the diagnosis of heterotopic pregnancy. ${ }^{9,10}$ Nearly half of the cases present with rupture, hemorrhage, and emergency intervention. Despite this, patients presenting with a viable IUP have a $70 \%$ chance of producing a living child if the diagnosis is made and treated appropriately. ${ }^{11}$ Treatment for heterotopic pregnancy typically involves laparoscopy and, most often a salpingectomy or salpingostomy. However, if the patient demonstrates hemodynamic instability, a laparotomy would then be indicated. Due to the inherent IUP that is viable, systemic methotrexate plays no role in the treatment of a heterotopic pregnancy. There have been some case reports of use of local injection of potassium chloride and methotrexate as well as case reports of expectant management but there seems to be a high rate of failure and there is little evidence to suggest these interventions currently. ${ }^{12-16}$

\section{CONCLUSION}

Heterotopic pregnancy though extremely rare can occur even in spontaneous conception. Hence, it requires a high index of suspicion for early and timely diagnosis and management. A timely intervention can result in a successful intrauterine fetus, thus preventing a catastrophe like tubal rupture and hemorrhagic shock which can be life threatening. Also medical facility must be alert to the fact that confirming an intrauterine pregnancy clinically or by ultrasound does not exclude the coexistence of an ectopic pregnancy that should systematically be suspected in any woman presenting with abdominal pain and hypovolemic shock during early weeks of pregnancy.

\section{Funding: No funding sources}

Conflict of interest: None declared

Ethical approval: Not required

\section{REFERENCES}

1. Tal J, Haddad S, Gordon N, Timor-Tritsch I. Heterotopic pregnancy after ovulation induction and assisted reproductive technologies: a literature review from 1971 to 1993. Fertil Steril. 1996;66(1):1-12.

2. Payne S, Duge J, Bradbury W. Ectopic pregnancy concomitant with twin intrauterine pregnancy: a case report. Obstet Gynecol. 1971;38:905-6.

3. Lautmann K, Staboulidou I, Wüstemann M, Günter H, Scharf A, Hillemanns P. Heterotopic pregnancy: simultaneous intrauterine and ectopic pregnancy following IVF treatment with the birth of a healthy child. Ultraschall Med. 2009;30:71-3.

4. Shavit T, Paz-Shalom E, Lachman E, Fainaru O, Ellenbogen A. Unusual case of recurrent heterotopic pregnancy after bilateral salpingectomy and literature review. Reprod Biomed Online. 2013;26:59-61.

5. Chadee A, Rezai S, Kirby C, Ekaterina Chadwick, Sri Gottimukkala, Abraham Hamaoui, et al. Spontaneous Heterotopic Pregnancy: Dual Case Report and Review of Literature. Case Rep Obstet Gynecol. 2016;214593.

6. Reece EA, Petrie RH, Sirmans MF, Finster M, Todd WD. Combined intrauterine and extrauterine gestations: a review. Am J Obstet Gynecol. 1983;146:323-30.

7. Pisarska MD, Casson PR, Moise KJ, DiMaio DJ, Buster JE, Carson SA. Heterotopic abdominal pregnancy treated at laparoscopy. Fertil Steril. 1998;70:159-60.

8. Damario. Ectopic Pregnancy. In: Rock, Jones III. Te Linde's Operative Gynecology. 10th edition. Philadelphia, PA: Lippincott Williams and Wilkins. 2011;794-5.

9. Jeon HS, Shin HJ, Kim IH, Chung DY. A case of spontaneous heterotopic pregnancy presenting with heart activity of both embryos. Korean J Obstet Gynecol. 2012;55:339-42.

10. Li XH, Ouyang Y, Lu GX. Value of transvaginal sonography in diagnosing heterotopic pregnancy after in-vitro fertilization with embryo transfer. Ultrasound Obstet Gynecol. 2013;41:563-9.

11. Rojansky N, Schenker JG. Heterotopic pregnancy and assisted reproduction--an update. J Assist Reprod Genet. 1996;13:594-601.

12. Bedaiwy MA, Volsky J, Lazebnik N, Liu J. Laparoscopic single-site linear salpingostomy for the management of heterotopic pregnancy: a case report. J Reprod Med. 2014;59:522-4.

13. Li JB, Kong LZ, Yang JB, Niu G, Fan L, Huang JZ, et al. Management of heterotopic pregnancy: experience from 1 tertiary medical center. Medicine. 2016;95:e2570.

14. Deka D, Bahadur A, Singh A, Malhotra N. Successful management of heterotopic pregnancy after fetal reduction using potassium chloride and methotrexate. J Hum Reprod Sci. 2012;5:57-60.

15. Baxi A, Kaushal M, Karmalkar H, Sahu P, Kadhi P, Daval B. Successful expectant management of tubal heterotopic pregnancy. J Hum Reprod Sci. 2010;3:108-10.

16. Goldstein JS, Ratts VS, Philpott T, Dahan MH. Risk of surgery after use of potassium chloride for treatment of tubal heterotopic pregnancy. Obstet Gynecol. 2006;107:506-8..

Cite this article as: Khanam R, Choudhury SA. Rare case of heterotopic pregnancy: a case report. Int J Reprod Contracept Obstet Gynecol 2022;11:610-2. 